\title{
EFFECTS OF RAMADAN FASTING ON HEALTH
}

M. G. Muazzam

\section{Introduction}

Fasting from dawn to sunset during the 9th lunar month of the Muslim calendar (Ramadan) every year is obligatory for all adult muslims, male and female. This religious fast known as 'Siam' in Arabic, means total abstention from food and drink and also smoking and sex during the period of fasting. The Quranic injunction regarding this is :-

"O those who believe, fasting is enjoined on you as it was prescribed for the people before you, so that you may be God-fearing, a certain number of days." (SLL : 183184)

Again, Allah reveals in the next verse when to keep fast as follows :-

"(Fast) in the month of Ramadan, in which was revealed the Gur'an, a guidance for mankind, and clear proofs of the guidance and the Criterion (of right and wrong). And whosoever of you is present, let him fast the month, and whosoever of you is sick or on a journey, (let him fast the same) number of other days-". (SII : 185)

So Muslims are fasting for one lunar month each year after this revelation in the early 7th century, but so far no one ever studied its effects on human health on a scientific basis.* Besides some so-called 'modern' Muslims, being influenced by the prevalent anti-religious culture of the West, often try to question the utility of the Ramadan fasting. Again, some physicians advise their patients not to keep fast without any valid reason and some even bvelieve that fasting can cause peptic ulcers though there is no scientific finding to support such a view.

In 1956, while undergoing post graduate training in pathology in the National Hospital, Queen's Square, London, the then.Professor of Pathology, Dr. J. N. Cummings, once told me that fasting in the summer may cause damage to the liver. In that year, fasting was about 19 hours long in London. I asked him if he had any scientific basis for such an assumption, for the Muslims were fasting for almost 1400 years, yet there was no reason to believe that as a nation they had bad livers. Professor Cummings then replied that he had no knowledge of any study on the subject but he thought that such a long fast, specially in summer, might damage the liver. On that occasion I promised that, Allah-willing. I would carry on research on the effects of Ramadan fasting, and I felt that such a study was essential.

On my return home in December 1957, I organised to carry on the study during the following Ramadan in 1958. This study was carried on for long six years, in different phases, from the Ramadan month of 1958 to that of 1963 in the Dhaka and Rajshahi Medical colleges. The following five colleagues were my co-workers and also co-authors in the publications in groups of one or two at a time in different phases of the study. They are :-

This study was carried on in 1958 , when the author was Demonstrator (Lecture) of Pathology. Dhaka Medical College. 
(1) Dr. Kazi Abdul Khaleque (2) Dr. Muhammad Nayeb Ali (3) Dr. Abul Hussain (4) Dr. Rafiqul Islam Choudhury and (5) Dr. Pervin Ispahani.

The results of our studies were published in six separate articles in different medical journals-three in the Journal of Tropical Medicine and Hygiene. London; two in the Medicus, Karachi and one in the Medical Bulletin, Rajshahi. Since the results of these studies should be of interest to the Muslim 'Ummah' in general, I am presenting the findings with relevant discussion in a form suitable for the general people as well. So far, it is the only work of its type, I hope that its publication will be worthwhile.

\section{Methods of Research}

The first study was carried out in the month of Ramadan of 1958, in the Pathology department of the Dhaka Medical college. The first batch of volunteers included 10 male and 3 female subjects and were obtained from the family members of my coworker, Prof. Khaleque and myself and the laboratory technicians of the department. One of the female subjects was pregnant with six months of gestation. One nonfasting male was taken as control. All the subjects were adults with an age range of 17 to 69 years.

A number of tests that could not be done in the first study were done in 1959 in the same institution. As the number of volunteers was small, the second phase of the study was carried out in the Rajshahi Medical College with a larger number of subjects, during the period of 1961 to 1963 . The place of study had to be changed as I was transferred to Rajshahi in 1961 where I could get the volunteers from the general pbulic in addition to some medical students.

All the studies were made during the month of Ramadan and all the subjects were practising Muslims accustomed to keep fast regularly.1 The reason for this was that all the formalities of fasting might not be possible in non-fasting months and fasting may not be strictly observed by non-fasting subjects. Non-Muslims were taken as control only.

In order to compare the results, tests were done one week before Ramadan in the morning before the breakfast, to provide the base line for later findings. During Ramadan, tests were done in the evening just after sunset before the daily fast had been broken by none other than by taking a sip of water for ceremonial breakfast. This timing was selected for identical time of test as during Ramadan, breaking of fast after sunset is equivalent to normal breakfast in non-fasting period.

For the first group, tests were done after the first day of fasting, at the end of the 10th day, 24th day and four weeks after the end of Ramadan. During the subsequent studies, the first and tenth day tests were omitted. The first day was chosen to see any remarkable effect due to fasting which is a complete change of normal habit. The tenth day was expected to give regular pattern developed due to continued fasting for sometime. As due to ensuing national holiday of Eid Al-Fitr after the end of Ramadan, many volunteers and laboratory workers start to leave the station in the fourth week of the month. we selected the 24th day of fasting as the last day for our study. We carried on the tests again after about a month of fasting period to see if the results returned to the base line. 
The following tests were done in different phases :

1) Physical :

i) Body weight; ii) Blood pressure; iii) Body temperature, respiratory rate and pulse rate; iv) Basal metabolic rate (BMR) and Electro-Cardiogram (ECG).

2) Biochemical - Estimation of :

i) Blood glucose: ii) Blood urea; fii) Serum cholesterol; iv) Serum calcium; v) Serum potassium; vi) Serum chloride: vii) Serum alkaline phosphatase; viii) Serum alkali reserve and ix) Plasma protein.*

3) Liver Function Tests :

i) Alkaline phosphatase estimation; ii) thymol and zinc sulphate turbidity tests.

4) Gastric juice analysis or Fractional test meal analysis.

5) Routine urine analysis and determination of 24 hours fluid intake and output.

6) Circulating eosinophil count - Hourly determination of eosinophil white blood cell in the peripheral circulation was done to assess if there was any significant evidence of strain due to altered daily routine in Ramadan. Blood was collected every hour from 9 a.m. till 4 p.m. from the fingers of fasting volunteers and nonfasting controls.

7) Glucose tolerance tests (GTT) were done with increasing doses of glucose meal to see if the rate of absorption of glucose (food) is increased after the day-long fast. This test was done on 4 elderly subjects. aged 40 to 69 years on three occasions at the end of the first, tenth and twenty fourth days of fasting. in the first phase of the study. ${ }^{1}$

8) Animal Experiments :-

In order to study any microscopic change in the liver due to day-long fast (as suggested by Dr. Cummings), we took 3 'test' cats and 3 'control' cats for experiment. We selected domestic cats for easy availability. Besides, cats are accustomed to human food, so that experiments will be on similar dietary conditions. The food was collected from the lady hostel of the Dhaka Medical College from the bone plates and excesses. The two groups of cats were kept in separate rooms and foods were provided at $9 \mathrm{a} . \mathrm{m}$ in the morning. The 'test' cats were allowed to eat for one hour and were made to fast untll $9 \mathrm{a} . \mathrm{m}$. the next morning. making the fasting period 23 hours. This was done to avoid inconvenience to provide food at odd hours. The 'control' cats were supplied fresh food every morning and allowed to eat $\mathbf{2 4}$ hours i.e. foods were kept before them all the time.

All the cats were again welghed on the 21st d day and killed after anaesthetising them with chloroform. Each animal was dissected, blood was collected for liver function tests and the liver was weighed and part preserved in fixative. Next day, the piece of liver was processed for histology.

\section{Experimental Findings or Results}

1) Physical Findings :-

i) Body weight-There was no significant variation in the body weight of the control subjects, the maximum variation being 2 pounds only. In the first

The advanced Seqological test like SGOT. SGPT, etc. were not introduced in 1958-65. 
phase, the number of test subjects was 13 and in the second phase 260 more volunteers were studied. Among the first grouping of 13 subjects, one elderly male had his weight constant throughout the study. The pregnant lady gained 4 pounds while the rest lost weight from one to seven pounds. ${ }^{1}$ Among the 260 subjects of the second group, $21(8.08 \%)$ showed no change of weight, 208 $(80 \%)$ lost weight at the rate of one to fourteen pounds while $31(11.92 \%)$ gained weight from one to four pounds. ${ }^{2}$ Out of the 208 who lost weight in the second group, only seven (3.37\%) lost from eleven to fourteen pounds and the remaining 201 lost from one to ten pounds. Thus out of 273 subjects in both groups, $219(80.22 \%)$ lost some weight but none of them complained of any weakness due to weight loss, rather a few overweight (obese) subjects expressed satisfaction on the loss of some body weight due to fasting.

Four weeks after the 'Feast' - Eid-Al-Fitr - half of the volunteers who lost weight regained their original weight.

ii) Body temperature, pulse and respiratory rates showed no appreciable change.

iii) Blood pressure was unchanged for almost all except a few who showed a slight fall with no ill effect or inconvenience to the subjects. ${ }^{1}$

iv) BMR was calculated by Read's formulal in the first phase and by Benedict-Roth instrument in the second phas. ${ }^{9}$ The pregnant lady showed a BMR of +15.1 after the first day and $+26,5$ after the end of 24 days. 1 There was no significant change in BMR of the remaining fasting subjects of both groups and their results were similar to those of the controls.

ECG was done on 11 fasting subjects before and after fasting, which showed no abnormality at all. ${ }^{3}$

\section{2) Biochemical Findings :-}

i) Blood sugar-All the fasting subjects showed a fall of blood sugar (glucose), the lowest range of fasting value being 68 to $104 \mathrm{mg} \%$. None of the volunteers complained of any symptom referable to hypoglycaemia. ${ }^{1}$

Glucose tolerance test (GTT) - There was no significant change in the glucose curve even with excess glucose meal. The variation of $-5 \%$ to $+10 \%$ was within normal limit. 1

ii) Blood cholesterol and blood urea were within normal range and the variation of values was negligible. 1

iii) Serum potassium, sodium, chloride, alkali reserve and calcium remained normal. ${ }^{1}$

iv) Plasma protein also showed no change. ${ }^{1}$

v) Liver function tests showed no abnormality. ${ }^{1}$

3) Haematological values - haemoglobin, packed cell volume (PCV) and erythrocyte sedimentation rate (ESR) showed no change due to fasting. ${ }^{1}$

4) Kidney Function Tests - Routine urine analysis showed no abnormality. Twenty four hours fluid intake and output showed normal water balance during fast. 1

5) Gastric Juice Analysis ${ }^{3.4}$ - During the month of Ramadan in 1959, gastric juice analysis was done on 7 fasting and 5 non-fasting subjects. The tests were done in the morning one week before Ramadan for base line and after the sunset 
(time for 'iftar'-breakfast) during the fasting period on the 24th day. Since the number of subjects was small, the tests were repeated subsequently in Rajshahi Medical College. Eighteen medical students incluing one female, aged 20 to 25 years, were selected as 'test' subjects and 3 as 'controls'. In $20(80 \%)$ of 25 fasting subjects in both groups, there was a distinct tendency of the gastric acidity of shifting towards normal range (isochlorhydria). Before fasting 14 had isochlorhydria 9 had hyper and 2 had hypochlorhydria. After 24 days of fasting. 20 showed iso, 5 hyper and 2 had hypochlorhydria. Out of 14 normal acidity, 3 became slightly hypeacidity with no complaint while, out of 9 hyperacidity, 7 became normal and 2 remained high and the 2 hyporacidity turned normal. The 'control' showed no change of acid pattern.

6) Circulated eosinophil count showed no efidence of stress except the usual diurnal variation. 5

7) Animal Experiment - There was no significant variation of body weight in both the groups of cats.It is interesting to note that 'test' cats did not loose weight even after 23 hours of dally fast. It seems that the animals adapted to the changed circumstances and took enough food during one hour meal time to suffice for the rest of the day.

Liver function tests and histological pictures of the liver showed no abnormality.

\section{Discussion}

1) i) From the result it is evident that Ramadan fasting is a slow and safe method of loosing body weight. None had any complaint due to loss of weight even though $3.37 \%$ of them lost from eleven to fourteen pounds. This is probably for a very slow rate of loss.

The excess body weight is known as obesity and it is one of the common problems of rich people all over the world, specially in the developed countries. Obesity is regarded as a potential factor for sudden death due to ischaemic heart disease in the modern world. Being obsessed by such ideas men and women, young and old, are now seriously trying to reduce or maintain lower body weight by different methods. In most of the holiday resorts and even in big metropolis, people of different ages are found jogging in the streets and parks in the morning and evening. Taking advantage of this attitude, some clever people are earning a good amount by preaching the advantage of yoga*. Obesity is no doubt a medical problem but medical science is still unable to provide a simple and workable method to deal with it. Modern medicine suggests the treatment of obesity by two methods : a) Use of de-appetiser drugs leading to less food intake and continuation of taking less amounts of food and b) prolonged starvation with sufficient amount of water and vitamins to lower the body weight drastically in a short time and to maintain that weight with low calorie diets. ${ }^{6}$ Both these methods are very difficult and often harmful to health.

It is a well known fact that the obese people are fond of food and to give them less food or lower their appetite will not be liked by them. Besides, such treatment needs constant medical supervition. Dr. Duncun of Philadelphia

A special type of physical exercise advocated by Hindu prists. 
Hospital treats his obese patients by witholding food for ten consecutive days except water, tea, coffee and vitamins. This causes rapid loss of weight. The patients are then given food of only 900 calories which is gradually increased to 1500 calories at which level the diet is maintained. Now an average healthy adult needs 2500 to 3000 calories per day, such a treatment cannot be carried out except in a hospital under the direct supervision of a competent physician. Since Ramadan fasting causes painless, harmless and slow loss of body weight, this type of fasting may prove better than the current medical methods for treating obesity. One may observe the Ramadan type of fast for a period necessary (one to six or even nine months each year) for the particular person. This will be easier to follow and no hospitalisation or medical supervision will be needed; the patient himself will be able to determine the length of time to fast (i.e. number of days) he needs. For obese patients it is wise to take a good night meal after 'alsha' prayer and a light meal or simply a glass of milk and water at' pr-dawn or 'sehri' time. Two full meals may delay the purpose and one full meal may be up to the liking of the patient. The importance of Ramadan type of fast instead of arbitrary period of fast is that, for a Muslim, it will be 'nafl' (extra) prayer and for the non-Muslims it will ensure strict regimentation which is essential to make it a success. Without such strict regulation one may be tempted to take some food in the form of a snack or drink, which will make the exercise useless. A religious strictness is important to avoid taking any food during the specified period of fasting in the day. The non-Muslims, however. may be allowed to take only water if they need in the day time.

About $8 \%$ of subjects maintained their weight unchanged and this is possible if usual food is taken during fasting month as Ramadan fasting is not starvation but change of meal time only. Another $11.9 \%$ of subjects recorded a small increase of weight, in spite of Ramadan fasting. which may be explained by the fact that some people try to take better quality food during Ramadan. Besides. in the month of Ramadan, the taking of meals is usually more regular than in other times of the year.

ii) The pregnant lady gained usual weight-four pounds in 4 weeks in spite of fasting which proves that, in normal pregancy, Ramadan fasting has no ill effects. In cases of complications like severe anaemia, excessive vomiting (hyperemesis gravidarum) eclampsis, oedema, marked albuminuria and high blood pressure or bleeding per vagina, fasting may not be possible as these are signs of illness. The ill persons are exempted from fasting.

iii) As body temperature, pulse rate, respiratory rate and blood pressure remained normal during fasting, it is evident that Ramadan fasting is harmless for normal adults. The slight fall of blood pressure as recorded by a few subjects was within the normal variation.

iv) Basal Metabolic Rate (BMR)-The BMR of all the fasting subjects except the pregnant lady remained within normal range, which shows that Ramadan fasting causes no metabolic change in the body.

Aisha prayer - Night prayer

Bangladesh Journal of Medical Science 17

Volume-4 (No.-3) 
The pregnant lady, showed normal rise of BMR as expected. Since this lady later on delivered a normal baby, it is evident that normal pregnancy is not a counter indication for Ramadan fasting.

v) Since the ECG of fasting subjects showed no abnormality, it is clear that this type of fasting has no 111 effect on the heart or its function.

\section{2) Biochemical Findings :-}

i) Blood sugar level-The normal blood sugar level in fasting condition in the morning is 80 to $120 \mathrm{mg} \%$ for normal adults. In our study this range was lower ( 68 to $104 \mathrm{mg} \%)^{1}$ than normal but never reached the danger level of below 60 $\mathrm{mg} \%$. So a healthy adult may safely fast in Ramadan without any danger of hypoglycaemia, a condtion characterised by sweating, palpitation, tremor. faintness, dizziness, diplopia, mental confusion leading to coma or unconsciousness. If one suffers from diabates mellitus of such severity that fasting for the required period leads to hypoglycaeemic symptoms, then such a person falls into the category of sickness and as such fasting is not obligatory.

In this connection, let us refer to the relevant Quranic verse :-

".........And whosever of you meets the month (of Ramadan) let him fast the month, and whosever of you is sick or on a journey (let him fast the same) number of other days. Allah desireth for you ease; He desireth not hardship for you and (He desireth) that ye should complete the period, and that ye should glorify Allah for having guided you, and that peradveture ye may be thankfull." (SII: 185)

From this verse it is clear that, if one is sick during the month of Ramadan and if fasting is expected to cause harm, then one needs not fast but will keep fast for the similar number of days after cure. Since sickness is a valid reason one needs not keep fast in diseases like severe diabetes, hight fever, jaundice and many acute conditions. This is a mercy of Allahas He desires ease for us not hardship. But mild sickness like common cold, slight injury or headache etc. should not be made an excuse to avold Ramadan fast. If the disease is incurable like cancer in advanced stage or luekaemia and fasting is not possible, then there is no question of doing it after the cure. In such cases those who can afford will feed a poor person as a compensation-one person for each day of fasting missed (Fedya), (a poor person will not pay 'Fedya')-another mercy of Allah.

The law of sickness is also applicable for journey (Safar) as enunciated by the Islamic Jurists. Majority Jurists opine that, if one can manage to keep fast during journey, there is no religious objection but it is not obligatory. When one will return home from journey (must be less than 15 days at a stretch) one will keep fast for the number of days missed. This is again the mercy of Allah who made these concessions for the believers.

ii) Glucose tolerance test or GTT showed normal absorption of glucose, which proves that Ramadan fasting causes no disturbance to the carbohydrate metabolism and there was no indication of glucose intolerance. The normal glucose 'meal' is $50 \mathrm{mgs}$ but we increased the dose up to $150 \mathrm{mgs}$ with no change in the blood sugar curve. ${ }^{1}$ 
iii) Other biochemical finding liver function tests were normal. So there is no evidence of any ill effect of Ramadan fasting on protein, fat and carbohydrate metabolism. Liver function was not disturbed at all.

3) Haematological findings, specially, normal ESR proved that Ramadan fasting does not cause any tissue damage.

4) Kidney Function Tests-Normal urinary findings and normal fluid balance prove that, in spite of total abstension from water or any fluid even in hot tropical countries (the study was done in Bangladesh when the fasting months were in the summer season). Ramadan fast has no ill effect on kidney function.

5) Gastric Juice Analysis-Normally gastric juice analysis is done in the morning in empty stomach which is actually fasting condition, as no food is allowed after the usual night meal. So during Ramadan the tests were done just after sunset at the time of normal 'Ifter' or ceremonial breaking of fast, to make the testing time comparable to normal procedure.

Since in 20 out of 25 fasting subjects the gastric acidity remained within normal range and $9(36 \%)$ abnormal acidity became normal after the fast, it is clear that Ramadan fasting is beneficial to abnormal grastic acidity. ${ }^{3-4}$ Besides, while $80 \%$ subjects maintained normal acidity following fast and only $3(12 \%)$ showed slight rise in acidity without causing any discomfort to the subjects.

The idea that fasting may cause rise of gastric acidity in normal persons is simply not true. Such an assumption is baseless and against the normal physiology of gastric acid secretion. It is an accepted physiological fact that fasting lowers the gastric acid so, one gets the lowest acid in the fasting sample taken out of the stomach in the empty state in the morning. The acidity begins to rise after the ingestion of a 'meal' in the form of $7 \%$ alcohol $^{20}$ or hot tea liquor ${ }^{25}$ without milk and sugar ${ }^{21}$. In a normal acid curve ${ }^{25}$ fasting value is lower than the values obtained after food. The second value is the lowest due to dilution of stomach juice by the 'meal'. Since Ramadan fasting is nothing but change of meal times the acid of the stomach should be reduced after day long fast. This is what we found in our study. The rise of acid in a small number of subjects may be due to some other factors. There is no scientfic reason to suggest that Ramadan fasting may have any harmful effect on gastric acidity. That $77.8 \%$ ( 7 out of 9 ) hyperacidity and $100 \%$ (total 2 subjects) hypoacidity became normal after Ramadan fast, provides scientific ground to suggest that Ramadan fasting is beneficial to abnormal acidity. This assertion is further supported by the fact that $78.5 \%$ (11 out of 14) subjects retained their normal acidity.

Peptic Ulcer-It is fashionable to blame the Ramadan fasting for increased performation of peptic ulcer in the month of Ramadan. ${ }^{10}$ Some even opine that fasting may cuase peptic ulcer. Up till now the cause of Peptic ulcer is not clear though, several possible factors are considered important. Our study proves that Ramadan fasting does not cause hyperacidity which is one of the factors considered responsible. So, one may reasonably be sure that Ramadan fasting has nothing to do with peptic ulcer. Besides, the prisoners of war in the German and Japanese camps during the Second World War though suffered from severe starvation did not show any increase in the incidence of peptic ulcer. ${ }^{19}$ 
Commenting on this, Dr. Cleave, a research scholar, stated with emphasis that "Fsting does not produce organic disease" and even starvation does not cause peptic ulcer. ${ }^{11}$

But though, Ramadan fasting should not cause peptic ulcer in healthy subjects, patients with active peptic ulcer should not keep fast, if fasting gives rise to pain in the abdomen. Peptic ulcer patients usually produce more hydrochloric acid in the stomach and this may happen even during fasting. Excess acid may damage the mucosa particularly in the ulcer area causing exacervation of the ulcer and may even lead to perforation of the duodenum or stomach(wherever the ulcer is situated). Such a perforation is a serious surgical condition and dangerous. As Allah clearly permits the sick persons not to fast, a patient with active peptic ulcer is exempted from fast. So, in spite of this clear injuction, if one keeps fast and suffers from perforation then, it is not the fault of Ramadan. Such unwanted over enthusiasm of excessive plety is against the teachings of Islam. This may result in the increase of perforation cases during the fasting month for which the institution of fasting for healthy persons should not be held responsible. If the apparent feeling of hyperacidity gives discomfort, fasting may lower the acid and the patient may feel better in Ramadan. In fact the person concerned should make his own decision to keep or not to keep fast. .

If fasting has got anything to do with peptic ulcer then Muslims as a nation should have higher incidence of peptic ulcer than the non-fasting nations. But the statistics show a different picture. Dr. Cleave in his book 'Peptic Ulcer'11 has given interesting findings. From his figures it is found that peptic ulcer is more common in non-Muslim majority areas like South India ${ }^{12,13}$ and South Nigeria, ${ }^{11}$ while it is said to be 'almost unnkown' among the Egyptian villagers (they are almost all Muslims), Northern Nigeria (predominantly Muslim) and very low among the people of pre-partitioned North West India (which includes preindependent Punjab and Kashmir where Muslims were majority). There was high incidence of peptic ulcer in the large numbers of non-Muslims as well as modern Muslims, many of whom are not strict followers of religion). He further reported that indigenous people of Indonesia (mostly Muslim) and Malaysia (mostly Muslim) have very low incidence of peptic ulcer in comparison to the foreign resident in these countries-Dutch, Chinese and Indians (mostly non-Muslims). Besides, in countries like Japan and England, incidence of peptic ulcer is much higher than most of the under-developed countries. This, according to Cleave, is due to use of refined sugars and cereals and the modern habit of taking irregular light meals or snacks, chocolates etc. The refined carbohydrates are devoid of natural protein which is an amphoteric substance and hence prevents sudden change of $\mathrm{pH}$ of the stomach contents. Dr. Cleave opines that removal of the protein helps in causing hyperacidity and repeated intake of food causes repeated increased production of gastric acid. This may be partly responsible for higher incidence of peptic ulcer among the people of developed countries and citizens of big metropolis in under developed countries who are accustomed to Western food and habit. Poverty, starvation and fasting are not at all responible for peptic ulcer. 
6) Stress in Ramadan-Ramadan fasting is supposed to cause extra stress on our system due to alternation of daily routine such as awakening in the late hours of night for late night meal (Sehri), remaining alert throughout the day against taking food and drink by mistake, the strict discipline of both physical and moral injuctions like avoiding irritation under all provocations and additional prayer (Salat al-Tarabih) at night etc. There is no specific laboratory test to detect stress except circulating eosinophil count and estimation of serum cholesterol level. ${ }^{23}$ Emotional stress may decrease the total eosinophil count. ${ }^{24}$ The circulating eosinophil count of the fasting subjects showed normal diurnal variation only. 5 So Ramadan fast did not show any detectable emotional stress.

7) Irritability - During Ramadan fasting some people may show slowing down of interest and efficiency and occasional irritability in the afternoon. This is due to hunger and those who are not accustomed to regular fasting are expected to show this slowness and irriability more than those who regularly keep fast each year. A good Muslim is required to keep fast in Ramadan to please Allah and he or she is advised by the Holy Prophet Muhammad (pbuh) to be patient during fasting and to avoid all sorts of arguments and quarrels. Besides, the purpose of this exercise of fasting is to acquire the good qualities of patience, forbearance, self-control and tolerance to be a "Muttaqui" (God-fearing) as desired by Allah (S 2:183).

Pr. Qureshi, ${ }^{7}$ the editor of 'The Medicus, Karachi.' while reprinting our papers on Ramadan already published in the Journal of Tropical Medicine and Hygiene. London, wrote in the editorial "That there is some slowing down of interest and efficiency and irritability found among some fasting subjects in the late hours of the fasting days; what is the cause of it? It is not due to lowering of blood glucose as there is no evidence of hypoglycaemia in fasting". We thought that it is due to relatively lower blood glucose but Dr. Queshi opines that the 'Dynamic stereotype of Pavlov, is probably responsible for such reactions. According to Pavlov, human beings are constantly exposed to nervous stimulation by their environment in the forms of quarrels, worries and anxieties, financial problems, sickness and death. political disturbances and even Inclement weather. Men adapt to these circumstances and this is termed as 'Dynamic stereotype' by Pavlov. If there is some addition to stimulations then the body adjusts to establish another steretype to the new situation. However, a small percentage of people may fail to do so. According to Queshi, such persons may fail to develop the new stereotype during Ramadan and may show the irritability and lack of interest and eficiency. He further states that it is for this reason probably, fasting is not obligatory for the children, sick persons, travellers and very old persons as, they will be unable to adapt to excess stimulation. However, the fact remains that in our study we found no evidence of extra stress in Ramadan.

\section{Benefits of Ramadan Fasting}

While asking the believer to keep fast in Ramadan, Allah emphatically declares 'And fasting is better for you if you did but know' (Sura 2 : verse 184) From our study already discussed above we have found certain benefits of 
fasting viz. lowering of body weight, normalisation of gastric acidity and adaptation to altered situation etc. Besides these there are some more indirect benefits :

1) Men may be compelled to suffer the pangs of hunger even if one is not poor, as in cases of war, communal riots, cyclone and floods, earthquake, being robbed of or stolen of on the way, land-slide, ship-wreck and plane crash etc. Those who are accustomed to yearly fasting will no doubt be in a better position to face the difficulties under such suden calamities than others. Besides, rich people may not realise the pangs of hunger suffered by the poor but a Muslim is trained by yearly fasting to understand the hardship caused by hunger. So practising Muslim - rich or poor - is expected to be more sympathetic to the poor and needy. Thus, Islam being a complete code of life trains its adherents for all eventualities in life.

ii) After the end of the month of Ramadan, the Muslims celebrate the breaking of fast by a great feast-Ed al-Fitr. Traditionally, Muslims prepare special dishes on the occasion. But a poor Muslim may not have enough means to enjoy this national feast. For this, the Holy Prophet (pubh) made a special poor-tax -sadaquat al-Fitr-which must be paid by those who can afford it, before the Eid prayer, in the morning on the day for 'Feast'. An amount equivalent to one meal for each family member of the rich (including the new born baby) must be paid during the last few days of Ramadan till the morning of the Eid day so that no poor in the locality remain unable to enjoy the 'Feast'. This amount is to be paid to those who are unable to pay this tax. This system is part of a social insurance for the needy.

ii) Islam declars that 'sadaqua' or payment of religious donations including 'Zakat' if paid in Ramadan is worth several times than paid in other months. As a result, rich Muslims pay their obligatory religious tax or 'Zakat' in form of money or clothes to the poor in Ramadan so that, on' the Eid day, every Muslim, rich or poor, can put on better or new clothes. Thus it is evident that the institution of Fasting in Ramadan has great and important social values.

Spectalities of Ramadan fasting-According to the Holy Quran (S 2:183). Allah prescribes fasting for the followers of all the religions revealed by Him before Islam. This is true for Judaism, Chritisanity and also Hinduism and Buddhism. But Ramadan fast has certain specialities not found in other religious fasts :

i) Ramadan fasting is obligation for every adult Muslim male and female, and it has been declared one of the five pillars of Islam. Fasting is not so universal and compulsory in other religions.

ii) 'Sehr' or late night meal-It is unique in Islam and a 'Sunnah' (traditioin of the Holy Prophet)-a special present of the Prophet to his followers. Fasting in Ramadan starts at dawn and the tradition is to take some food and drink about 1 to $11 / 2$ hours before sun rise; this is known as 'Sehr'. This is however not obligatory but as a respect of the Holy Prophet and the personal benefit of those who fast, one is expected to take some food and/or some milk or water at Sehr time. In fact most do take food at Sehr. This is scientific in the sense that such 
a late night meal and drink will no doubt minimise the hunger and thirst during fasting period and help maintain fluid balance. This tradition is based on the declaration of Allah in the Holy Quran that "Allah desireth for you ease, He desireth not hardship for you", (S 2:185) and Sehr makes the fast easier.

iii) 'Salat al-Tarawih'-During Ramadan additional 8 to 20 'raka' extra prayer is a sunnah after normal 'Eisha' or night prayer. Some may think that, after a daylong fast when one is already tired, this extra prayer is a burden on the fasting subjects. But, in fact, this is very helpful. The usual routine in Ramadan is to take breakfast after the sun set, then to offer usual evening prayer-of 'Maghrib' and then to take some rest. After about two hours of the sun set, normal night prayers of 'Eisha' is offered. Along with this, an extra lengthy prayer 'salat altarawih' is offered in congregation (though congregation is not obligatory) which takes about one hour of extra time. The evening meal after the day long fast may be a little heavier than usual. So a rest for about two hours is good for health. Often people feel a bit drowsy after a heavy meal at breakfast as most of the circulating blood is in the brain. So this rest is quite physiological. But if one goes to sleep without further exercise, there is a chance of trouble with digestion and one may not get hungry at the time of Sehr. So a mild exercise in the form of salat al-tarawih helps proper digestion and removes the feeling of lethargy and tiredness. In fact this mild exercise is in accordance with the advice of the Holy Prophet-'after dinner rest a while and after supper walk a mile', So salat altarawih is not a burden, rather it is beneficial to health.

iv) Ramadan fasting is total fast during the day while fasting in other religions are not of any set pattern. Besides, in some types of fast, fruit and milk and water etc. may be taken. All the rules and regulations of Ramadan are based on guran and the traditions of the Prophet (Sm).

None of the religious fasting should be considered as starvation. the political fasts are apparently voluntary starvation but in fact these are not total fast as they usually take milk and water and even fruit juice. The political fast of Mr. Ghandhi of India, Khan-Abdul Ghaffar of Pakistan and Mawlana Bhashani of Bangladesh was for political pressure on the Government. So such fasts are quite unlike Ramadan fast.

v) Rules relating to health in Ramadan-It is interesting to note that all rules and regulations regarding Ramadan fast concern our health. This is quite natural as Islam is a complete code of life and good health is essential to fulfil the obligation of Muslim. The important such rules are :

a) Fasting is not obligatory for the children, very old and persons of unsound mind as long abstention from food and drink may be harmful to health. Besides, such persons may not be in a position to observe the rules of fasting.

b) The tradition of early 'iftar' (breakfast) and late 'sehr' are meant to avoid any harm to health.

c) Sick persons, menstruating women and mothers of suckling baby (if fast reduces breast milk) are exempted from fast to be completed the required number of days after cure, end of period and after weaning of the child respectively. 
d) A traveller is also exempted from fast due to possible inconvenience of taking regular food, timely sehr and ifter besides the troubles of travelling itself. of course, if one is able to fast while travelling, there is no objection.

e) The tradition of salat al-tarawih is useful as a mild exercise which helps in proper digestion and removal of lethargy.

vi) Another important speciality of Ramadan fasting is its observancd according to lunar calender instead of usual solar calender. So, fasting months rotate throughout the solar year, advancing about eleven days each year. As a result, Ramadan comes to all the seasons of one's country by turn and one keeps fast in both the hot and cold seasons of one's country so that one faces both longer and shorter days of the area for fasting. This is a great sign of universality of Islam and justifies the claim that Islam is for the whole mankind all over the world. If solar calender would be observed then in the northern and southern hemispheres fixed season-hot or cold (summer or winter) would remain constant for fasting. This would compel Muslims of some area to fast always in hot and longer summer days while others in their areas would be complled to fast always in cold and shorter winter days. Such an arrangement would be a negation of Universility of Islam.For example, one may note that Christmas in Europe is always celebarated in severe winter and snow, while in Australia and New Zealand it is celebrated in bright Summer.

\section{Conclusion}

A Muslim keeps fast in Ramadan because this is obligatory on him as per Guran which he believes to be the revelation of Allah. He does not care whether fasting will be helful or harmful to his health but will keep fast if he can physically afford. But some non-Muslims and doubters among the so-called Muslims try to suggest that fasting may harm our health. In order to allay such doubt we undertook the above study. From our study it is clear that 'Fasting is indeed beneficial to us physically. mentally and socially and there is no harm to a healthy adult on whom the fasting is obligatory. Besides, Ramadan fasting is also a symbol of universality of Islam'.

\section{References}

1. Muazzam, M.G. and Khaleque, K.A. (1959). Effects of Fasting in Ramadan, Journal of Tropical Medicine and Hygiene, London, 62, 292.

2. Muazzam, M.G. and Ali, M.N. (1967). Effects of Ramadan Fasting on Body Weight, The Medicus, Karachi, 34, 134.

3. Khaleque, K.A., Muazzam, M.G. and Ispahani. P. (1960), Further Observations on the Effects of Fasting in Ramadan, J. Trop. Med. \& Hyg. 63, 241.

4. Muazzam, M.G.. Ali. M.N. and Husain. A. (196 3). Observations on the Effects of Ramadan Fasting on Gastric Acidity. The Medicus, 24, 228.

5. Khaleque, K.A. Muazzam, M.G. and Chowdhury, R.I. (1961). Stress in Ramadan Fasting. J. Trop Med. \& Hyg. 64, 277.

6. Clark, B. (1963. Fasting : Swift Sure Way to Loose Weight, The Readers Digest, March issue, English edition, 45.

7. Qureshi, M.S. (1963). On Fast, Farce and Starvation, The Medicus, 25278 .

8. Pavlov, I.P. (1955t. Selected Works, Foreign Languages Publishing House, Moscow. 
9: Muazzam, M.G. Ali, M.N. and Husain, A. (1966). Effect of Ramadan Fasting on Basal Metabolish. Medical Bulletin, Rajshahi, 3,1.

10. Hussain, M.A. (1966). The Medicus, Karachi, 28,1.

11. Cleave, T.L. (1962). Peptic Ulcer. John Wright \& Sons Ltd. 1st edition, Bristol.

12. a) Dogra, J.R. (1940). Ind. J. Med. Research, 29,2,

b) Dogra, J.R. (1941). Ind. J. Med. Research, 29, 665.

13. a) Konstam, P.G. (1958). Schwelz Z. allg. Path., 21, 229.

b) Konstam, P.G. (1959). Ind. Med. Science, 13, 486.

14. Koywenaar, W. (1930). Med. T. Genesk, 74, 2321.

15. Vine, L.E. (1937). J. Malaya-British Medical Association, 1,2.

16. De Langen, C.D. Lichtenstein. A. (1936). A Clinical Text Book of Tropical Medicine (first English edition from revised 3rd Dutch edition), Amsterdam, Koiff.

17. Kurokawa, T. and Okabayashi, A. (159). Acts Path. Jap. 8. 297.

18. Doll, W.R.S., Jones, F.A. and Buckatzseh, M.M. (1950). Spec. Rep. Ser. Med. Res. Counc1l, London, no, 276.

19. Glatzel, H. 1(1952). Artz. Wschr. 7, 1063.

20. Bell, (1922), Guy's Hospital Report, 72, 302.

21. Muazzam, M.G., Khan, A.K. and Nabi, M.N. (1967). Tea-liquor as 'Test Meal' in Fractional Gastric Juice Analysis, Teh Medicus, 35, 51.

22. Pickthall, M.M. (1977). Teh Glortous Gur'an, World Muslim League-Rabita, Makkah, Kingdom of Saudi Arabia.

23. Kleinsorage, H. (1960). Med. Klin. 26, 1177.

24. Wintrobe, M.M. (1956). Clinical Haematology, 4th edition, Lea and Ferbiger. Philadelphia, 228.

25. Muazzam, M.G. and All, M.N. (1964). Observations on the Normal Gastric Acidity in Young Adults of East Pakistan, J. Pak. Med. Ass'n vol XIV, No. 8, 431. 